\title{
O DELINEAMENTO DE UMA PESQUISA EM IMAGENS E AUDIOVISUAIS NA CIÊNCIA DA INFORMAÇÃO: O "TAGUEAMENTO" COMO QUARTA DIMENSÃO
}

\section{THE DELINEATION OF AN IMAGE AND AUDIOVISUALS RESEARCH IN INFORMATION SCIENCE: TAGGING AS THE FOURTH DIMENSION}

Rosa Inês de Novais Cordeiro ${ }^{a}$

\footnotetext{
${ }^{a}$ Doutora em Comunicação e Cultura pela Universidade Federal do Rio de Janeiro (UFRJ). Professora da Universidade Federal Fluminense (UFF). E-mail: rosanovais@id.uff.br
} 


\section{RESUMO}

Introdução: Abordam-se quatro dimensões convergentes no delineamento de uma pesquisa em imagens e audiovisuais na área da Ciência da Informação e, em particular, no contexto da organização da informação visual.

Objetivo: Apontar que um estudo de imagens e audiovisuais se substancia com maior densidade quando as seguintes dimensões são ponderadas/clarificadas na pesquisa: a especialidade da Ciência da Informação envolvida, bem como as áreas de interface ou campo operacional eleito; a natureza do corpus de análise; os cenários sociais, culturais, econômicos, entre outros, relacionados, em ambientes informacionais físicos ou digitais; e o estado da arte da literatura.

Metodologia: Reflexão teórica a partir da literatura que aborda a indexação para a representação e o acesso do objeto de estudo em ambientes de informação.

Resultados: As quatro dimensões impactam na determinação das variáveis que devem ser consideradas em uma pesquisa sobre informações visuais e nos resultados alcançados, tendo em conta que esse universo de informações é gigantesco e repleto de peculiaridades. No que tange à quarta dimensão destacam-se na literatura sobre imagem e audiovisuais no âmbito da indexação e busca da informação, os artigos sobre o "tagueamento" colaborativo/social, os quais tentam determinar a relação cognitiva da atribuição de tags (etiquetagens livres) nas consultas.

Conclusões: Na literatura analisada percebe-se a abordagem de três das dimensões mencionadas, contudo a dimensão da problematização e caracterização dos cenários carece de uma maior exposição.

Descritores: Pesquisa em imagens. Pesquisa em audiovisuais. Indexação de imagens. Indexação de audiovisuais. "Tagueamento" colaborativo/social.

\section{INTRODUÇÃO}

Este artigo ${ }^{1}$ se situa no contexto dos estudos de imagem e audiovisuais em Ciência da Informação. É realizada uma reflexão teórica a partir da literatura selecionada que trata da indexação profissional e do "tagueamento" (tagging) para a representação e o acesso de imagens e audiovisuais em ambientes de informação.

Abordam-se quatro dimensões convergentes para o delineamento de uma pesquisa nesse domínio do conhecimento e, em particular, no contexto da organização da informação visual".

\footnotetext{
1 Este artigo foi desenvolvido em decorrência da palestra realizada no II Colóquio em Organização, Acesso à Informação e Conhecimento (II COAIC em 2017), na mesa redonda sobre métodos de pesquisa em análise de imagens.

${ }^{2}$ Corresponde à marcação (etiquetagem ou identificação) de um item de informação em linguagem livre em ambiente web, em oposição à nomeação dos registros em linguagem controlada. Quer dizer, os usuários/internautas indicam palavras escolhidas livremente (palavras-chave) para descrever ou categorizar o conteúdo digital.
} 
Considera-se que estudos de imagens e audiovisuais se substanciam com maior densidade quando quatro dimensões são ponderadas e clarificadas na pesquisa: a especialidade da Ciência da Informação envolvida, bem como as áreas de interface ou campo operacional eleito; a natureza do corpus de análise; os cenários sociais, culturais, econômicos, entre outros, relacionados, tanto a ambientes informacionais físicos ou digitais; e o estado da arte da literatura.

Os artigos selecionados para o embasamento teórico da discussão tiveram como critério a aproximação temática de artigos resultantes principalmente do Journal of the American Society for Information Science and Technology, Journal of Documentation e Journal of Information Science. Também recorreu-se a alguns capítulos da publicação de Foster e Rafferty (2016), intitulada Managing digital cultural objects: analsyis, discovery and retrieval.

$\mathrm{Na}$ tentativa de situar o objeto cultural do qual vai-se tentar aproximar e procurando não entrar no mérito da discussão sobre os modelos teóricos dominantes na área (denominados, muitas vezes, como modelos positivista, cognitivo e sociológico), pode-se recorrer a qualquer um dos autores tradicionais da Epistemologia da Ciência da Informação para chegar a alguns aspectos consensuais.

Um deles se refere ao objeto de investigação da área, que diz respeito ao "estudo das propriedades gerais da informação (natureza, gênese [produção] e efeitos)" na sociedade agregando-se evidentemente o contexto (social e cultural, etc.) no qual tal fenômeno acontece. Ou seja, "a análise dos processos de construção, comunicação, uso e [acesso] da informação; e a concepção dos produtos e sistemas que permitem sua construção, comunicação, armazenamento e uso". (LE COADIC, 1996, p. 26).

Conforme Salaün e Arsenault (2009), no manual de introdução à Ciência da Informação da Universidade de Montreal, que é de forma constante citado na área, e igualmente posto por Araújo (2014), o documento é apresentado sob três perspectivas: a sua forma (o signo, aquilo que the confere existência material, que o torna perceptível, o seu conteúdo (o texto [mensagem] que faz 
dele algo inteligível), e o meio (ou a relação, o uso social). "A informação é a resultante das ligações entre essas dimensões, embora, ao longo dos anos, subáreas da ciência da informação tenham privilegiado uma ou outra destas dimensões" (ARAÚJO, 2014, p.145).

Para Rendón-Rojas (2012, p.10), sobre objetos, sujeitos e processos que habitam o campo da informação:

[...] a raiz ontológica que justifica a possibilidade do consenso na comunidade científica em estudos da informação é a existência de um campo fenomênico bem determinado que é o campo da informação documental no qual habitam objetos (informação, documentos, unidades, fontes, fundos de informação), sujeitos (usuários, profissionais da informação documental) e processos (geração, coleta, processamento, armazenamento, busca e recuperação, disseminação e uso da informação).

Portanto, ao contrário, de outras áreas, a questão do objeto cultural, o documento, faz parte das questões de pesquisa da Ciência da Informação. Contudo, a perspectiva de análise do problema de pesquisa deve estar claramente definida. $\mathrm{O}$ uso ilustrativo de imagens em um artigo, muitas vezes não o caracteriza como estudo de imagem. Acentua-se este aspecto, considerando a ponderação realizada por Ulpiano Meneses (2003, p. 26) no domínio da história quando cita a "impropriedade de conformar a modalidade de pesquisa à natureza da fonte e não do problema histórico", ou seja, do problema de pesquisa em si.

É normal e legítimo que projetos de investigação histórica surjam da descoberta ou reavaliação de fundos documentais ou coleções tipologicamente bem definidas e possam deles partir. No entanto, o próprio projeto de pesquisa deve estabelecer uma relação dialética permanente entre documentos e problemática histórica [problemática da pesquisa], mas ao cabo é esta última que deve predominar (MENESES, 2003, p.28). 


\section{A ESPECIALIDADE DA CIÊNCIA DA INFORMAÇÃO ENVOLVIDA: PRIMEIRA DIMENSÃO}

Em consequência, nesse universo da geração, fluxo, comunicação, uso e acesso da informação modelam-se (configuram-se) as especialidades da área. Mais uma vez, pode-se trazer à lembrança diversos autores para constatar a sistematização, o desenho dessas especialidades. Naturalmente que isto é mapeado aplicando-se diferentes procedimentos de pesquisa, como por exemplo, a observância à recorrência aos temas de artigos publicados mediante análises métricas, análise de grupos de pesquisa do Conselho Nacional de Desenvolvimento Cientifico e Tecnológico (CNPq), a observância dos grupos de trabalho (GTs) dos Encontros Nacionais de Pesquisa em Ciência da Informação (atualmente são onze GTs temáticos) e produção intelectual resultante, entre outros.

Entretanto, acentua-se a complexidade que esses estudos sempre envolvem e em particular quanto à precisão e ao detalhamento temático. Para confirmar, pode-se explorar a situação do Esquema de Classificação que foi elaborado por Dahlberg (1993), somente para a especialidade da Organização do Conhecimento, onde são apresentados dez grupos principais (classes) de 09 com suas várias subdivisões.

Pois bem, uma vez apontada de forma muito sucinta a questão da especialidade da Ciência da Informação eleita, indagamos:

- O problema de pesquisa envolvendo o objeto cultural será estudado

(pertencente) sob qual especialidade/domínio da Ciência da Informação?

Por exemplo: Organização do conhecimento e da informação? Preservação do audiovisual? Patrimônio audiovisual? Capacitação do profissional da informação em imagens e audiovisuais? Economia da informação? Indústria audiovisual?

- Qual será o domínio do conhecimento (a área) de interface?

Por exemplo: Análise fílmica (Cinema)?

- Que áreas de interface ou campo operacional serão eleitos como um ângulo estratégico de observação do fenômeno (antropologia visual, 
sociologia visual, história cultural, história da fotografia, semiótica, psicanálise, fenomenologia) provocam influência em campos afins.

\section{NATUREZA DO CORPUS DE ANÁLISE: SEGUNDA DIMENSÃO}

Em diferentes áreas, vê-se que a fotografia e os produtos audiovisuais particularmente ligados ao cinema têm sido constantemente objeto de estudo. Contudo, o universo é bastante amplo. Daí a necessidade de especificar as características desses objetos culturais (álbuns de família, "livro de artistas", entre outros), ou seja, o gênero de imagem, o tipo de objeto cultural. $O$ contexto dos documentos imagéticos e audiovisuais é muito amplo e reúne singularidades quanto às circunstâncias de produção, circulação, uso e suas interações, além da constituição dos acervos e coleções.

Meneses (2003, p. 18) menciona: "Daí também a importância de retraçar a biografia, a carreira, a trajetória das imagens".

Sobre o conhecimento do contexto de produção, a trajetória e os efeitos dos objetos culturais (das imagens ou dos filmes), pode-se relacionar 0 comentário de Lima (1988, p. 14) no momento em que explica a validez desse conhecimento "tanto para uma fotografia de família como para uma fotografia de imprensa ou mesmo para uma fotografia histórica. Esses conhecimentos prévios se fazem visíveis [...] na fase de [análise] interpretação do fato registrado em imagem".

Neste momento é importante rememorar uma citação de Borges (2005, p.81) referente ao resultado de uma fotografia, quando menciona "que uma dada imagem é a representação do mundo que varia de acordo com os códigos culturais de quem a produz".

\section{OS CENÁRIOS: A TERCEIRA DIMENSÃO}

A abordagem neste item será quanto aos vários cenários sociais, culturais, econômicos, políticos, tecnológicos, entre outros, relacionados, que constituem os ambientes informacionais físicos ou digitais. 
Neste momento, este artigo particulariza o esforço de reflexão considerando o ambiente de pesquisa que intervém, em torno do ato de pesquisa em imagens e audiovisuais, ou seja, o que denominou-se, em alguns momentos, como objetos culturais ${ }^{3}$ no âmbito da documentação cultural digital.

Verificou-se no ambiente da web um número enorme de websites sobre imagens em movimento com diferentes propostas. Em consequência, diversos cenários se apresentam no que concerne à sua organização, interface com o usuário e estratégias de acesso. Na literatura de Ciência da Informação variados estudos abordam a questão do comportamento de uso das imagens pelos demandantes nos serviços de informação, na interação homem-máquina.

Em La Barre e Cordeiro (2016), relataram-se os cenários que se configuraram mediante busca digital de filmes (vídeos) realizada nos sites do British Film Institute (BFI), American Film Institute (Al), Internet Movie Database (IMDb), YouTube e Netflix. Parece pertinente tecer comentários sobre a classificação desses cenários, que podem ser detectados e classificados de distintas maneiras. Eles foram assim sistematizados:

- Instituições centradas na custodia, memória e preservação, as quais podem ser denominadas de unidades de memória e informação: British Film Institute, American Film Institute, Bibliothèque Nationale de France, Internet Archive: Moving Image Archive, entre outras.

- Empresas centradas (orientados no oferecimento) no serviço: Criterion Collection, iTunes, Netflix, entre outras.

- Serviços centrados (orientados) no compartilhamento: Vimeo, YouTube, IMDB e Rotten Tomatoes, entre outros.

$\mathrm{Na}$ referida pesquisa, tentou-se também analisar nesses websites as orientações que eram fornecidas aos usuários quanto ao uso das palavraschave, vocabulários controlados, critérios aplicados na arquitetura e na categorização dos itens ou pontos de acesso, bem como na elaboração de resumos ou sinopses. Isto é, a declaração das diretrizes que foram estipuladas

${ }^{3}$ Cf. "objetos culturais digitais" expressão usada por Foster e Rafferty (2016), englobando diversos objetos não-textuais, incluindo imagem, música e imagens em movimento (documentação cultural digital). 
para o estabelecimento da política de indexação visando à representação da informação em um ambiente de informação. Essas diretrizes são capazes de informar aos usuários sobre os critérios adotados pela instituição na determinação dos campos de tratamento, da seleção do nível de análise dos documentos (filmes) condensados (aspectos indexados e critérios para elaboração dos resumos/sinopses), os fundamentos que estão presentes na arquitetura do website e nas descrições e categorizações do material incluído, assim como as demais ações necessárias à otimização de acesso ao sistema.

Considerando os cenários analisados nos ambientes web de filmes, pode-se reafirmar a natureza distinta dos objetivos institucionais dos três cenários estudados. O primeiro cenário mostra a preocupação das instituições com a custodia de acervos para a preservação e a memória filmográfica de um pais. Há um cuidado especial na descrição e na representação dos itens do acervo. O segundo cenário expõe empresas voltadas para a comercialização de serviços e produtos, cuja sobrevivência depende de quem usa. É interessante notar que a continuação de um serviço como YouTube é dependente do criador de conteúdos, onde uma mesma pessoa produz e consome a informação (vídeo). É bem verdade que muitos dos vídeos acessados certamente não são assistidos na sua integralidade. É curioso constatar como o Netflix, que depende de seus assinantes para a manutenção do serviço, tenta de forma robusta conhecer e ampliar o perfil de interesse dos clientes.

De outro modo, como é realizada essa procura sistemática pelos interesses dos demandantes de um serviço é um dado pouco esclarecido nos ambientes de informação voltados para a custódia, memória e preservação de acervos (unidades de memória e informação).

Nos cenários analisados, cujo universo de informações visuais, além de vasto, é repleto de particularidades, encontramos duas situações que demandam especial atenção na área da Ciência da Informação e dizem respeito à interface do sistema:

a) reconsiderar como os acervos ou as coleções estão sendo organizados e gerenciados nos websites, pois, por exemplo, muitas vezes são 
propostas categorizações muito amplas que demandam do usuário várias tentativas para a localização do documento audiovisual desejado, tal qual o gênero documental do filme. Já existem na área algumas possibilidades teóricas que poderiam ser mais testadas na organização digital desses documentos e outrossim lançarmos mão das parcerias mais intensas das curadorias especializadas.

Rafferty (2016, p. 3) assinala que o gerenciamento dos objetos digitais tem sido considerado por acadêmicos de diversos campos, como da Ciência da Informação, Arquivologia, Mídia e Comunicação, Ciência da Computação entre outros. Porém, adverte que o desafio não é somente técnico, mas muitas vezes relacionado aos aspectos semânticos (como as abordagens semânticas de indexação) e comunicativos dos objetos culturais. A autora enfatiza que esses desafios semânticos e interpretativos são há muito tempo identificados na literatura e cita como exemplo o livro clássico do Langridge (1989), intitulado Subject analysis: principles and procedures. Isto é, no universo digital exacerbam-se os problemas relacionados à organização classificatória dos objetos culurais e o acesso aos seus conteúdos.

b) intensificar o "tagueamento" fornecido pelo usuário ("tagueamento" colaborativo/social) no qual princípios de indexação sejam considerados. Notase que nesse contexto as práticas para a nomeação dos documentos na internet são muitas vezes citadas como "indexação", contudo não levam em conta qualquer técnica da área, nem mesmo é ponderada a diferença entre a indexação por palavras e a indexação por conceitos. A relevância dos conceitos significativos de um documento (vídeo) é totalmente esquecida, sobressaindo o "tagueamento" emocional e circunstancial. Em um fluxograma sobre as operações de indexação para a representação do conteúdo temático, Wellisch (1995, p. 230) a partir de norma da International Organization for Standardization (ISO), estabelece como etapas iniciais o exame do documento e a identificação dos conceitos significativos. Cabe assinalar que iniciativas colaborativas para a descrição e a representação dos vídeos (determinação de pontos de acesso e palavras-chave, resumos, dentre outros) são de grande importância. Estas poderão ser implantadas nos serviços de informação a partir 
de uma política de indexação e vocabulários estabelecidos, sendo municiados pelos estudos que procuram determinar a relação cognitiva da atribuição de tags (etiquetagem livre) nas consultas, para fins igualmente da projeção de modelos e implementação de algoritmos usados nos sistemas. Foi curioso observar no Youtube uma série de recomendações que se aproximam de alguns procedimentos de indexação, cujo intuito é promover cada vez mais o acesso a determinado canal, ampliando o número de visualizações e o "fortalecimento" do canal mediante inscrição e comunidade de seguidores que avaliam e compartilham o canal.

Outro procedimento que desperta interesse é o adotado pelo American Film Institute (AFI), o qual possui uma rede acadêmica colaborativa para a descrição e a representação de filmes americanos no seu banco de dados online que pode ser acessado no Catálogo AFI. O objetivo da instituição é a organização e a preservação do patrimônio cinematográfico americano incluindo filmes (longas e curtas metragens) produzidos nos EUA ou financiados por empresas de produção norte-americanas. AFI Catalog of Feature Films (1893-1993) contém informações sobre elenco, equipe técnica, resumos, assuntos, gêneros, fontes bibliográficas e notas históricas. Nem todos os filmes estão com os resumos da trama/enredo (plot summaries), mas afirmam que o projeto do American Film Institute Catalog foi acelerado "com a publicação de cerca de 10.000 novos registros de filmes produzidos e lançados entre 1975 e o presente". Para estimular esse esforço estabeleceram uma rede acadêmica, no qual jovens pesquisadores de instituições universitárias participantes do projeto (Emerson College em Boston, Instituto de Tecnologia da Geórgia, Universidade da Califórnia em Los Angels, Universidade de Pittsburgh e Universidade do Texas em Austin) fornecem informações referentes ao resumo e notas de produção dos filmes para ajudar na elaboração dos "registros básicos" do material. Até à data, centenas de títulos foram atribuídos à rede acadêmica, e essas entradas foram "recebidas, editadas e postadas com crédito apropriado aos alunos e seus orientadores acadêmico" (AMERICAN FILM INSTITUTE, 2017). 
Constata-se o relevante trabalho que o AFI realiza quanto à rede acadêmica colaborativa para a descrição e a representação dos filmes na internet, destacando-se os pontos de acesso referentes ao resumo, aos assuntos e às notas. Todavia, não se detectaram no site informações sobre os princípios e os instrumentos usados para a descrição dos campos, bem como para a nomeação dos assuntos e critérios usados para a elaboração dos resumos. Portanto, não foi possível identificar a explicitação da adoção de política de indexação.

\section{O ESTADO DA ARTE DA LITERATURA: O "TAGUEAMENTO" COMO QUARTA DIMENSÃO}

Quanto ao estado da arte da literatura referente aos estudos em imagem e audiovisuais no âmbito da indexação e busca da informação, observou-se reincidência de artigos sobre o "tagueamento" colaborativo/social, os quais abordam, entre outros aspectos, a relação cognitiva da atribuição de tags (etiquetagem livre) nas consultas.

No espaço audiovisual e de imagens da web, o universo de documentos visuais configura uma gama de ambientes informacionais de naturezas diversas, porém com peculiaridades significativas em referência às suas características de produção, constituição e estrutura informacional, uso e reuso, dentre outras. Soma-se a isso, a problemática do momento atual, no qual fica cada dia mais instável a identificação pelos serviços de informação dos possíveis perfis de interesse dos demandantes (usuários/internautas), bem como o seu espaço cognitivo no processo da busca de itens de informação. Observa-se também no primeiro cenário citado, as instituições de memória, o emprego de padrões internacionais para a recuperação de itens de informação nos catálogos de bibliotecas como o modelo Functional Requirements for Bibliographic Records (FRBR).

No tocante aos tipos de acervos de imagens, Jörgensen (2016, p.158) comenta que as bibliotecas e os museus usam imagens digitais como um recurso para aumentar a conscientização dos usuários sobre itens únicos das 
coleções e para revelar (divulgar) coleções "escondidas", ou seja, que não estão em exibição pública. Cita o caso do projeto Steve.museum, no qual avaliou-se o potencial da prática do "tagueamento" para aumentar o acesso e incentivar à interação do usuário com a coleção do museu.

Rorissa e lyer (2008) realizaram estudo sobre a relação entre teorias da cognição, em particular da teoria denominada do nível básico e a categorização de imagens por internautas, que objetivava enfrentar o problema de indexação de imagens para fins de navegação. Concluíram que a teoria do nível básico é apropriada para entender a categorização humana e a concepção de taxonomias, ontologias, interfaces de navegação e outras ferramentas e sistemas centrados no usuário. Verificaram que as nomeações das categorias de imagens foram realizadas do nível superordenado para o nível básico, e são genéricas e interpretativas, sendo raramente empregadas as categorias de nível subordinado. No artigo, apresentam uma sistematização dos níveis categorizados (superordenado, básico e subordinado) e definições. Ali apontou-se que o "tagueamento" poderia ser uma alternativa ou servir de complemento para a indexação profissional, contudo os autores ressaltaram a necessidade do desenvolvimento de maior número de pesquisas, a fim do entendimento da natureza das tags que as pessoas usam para imagens individuais ou grupos de imagens, abrangendo o nível de abstração das tags.

Diante disso, acredita-se na importância do desenvolvimento de diretrizes que levam em conta além do potencial informativo dos documentos, o comportamento de busca da informação no ambiente web e dentro desta temática parece producente agregar as pesquisas que visam compreender a relação cognitiva da atribuição de tags (etiquetagem livre) nas consultas.

Ampliando-se a discussão para imagens de uma forma geral, verifica-se na literatura, de forma recorrente, produtivos estudos em Ciência da Informação que investigam as imagens e os audiovisuais no domínio da organização do conhecimento e representação da informação. Acrescentam-se ainda as pesquisas preocupadas com a recepção da imagem pelo usuário mediante atribuição de tags ou consultas de imagem na web, ou melhor, o "tagueamento" social/colaborativo, como as realizadas por Ransom e Rafferty 
(2011), Bar-Ilan et al. (2012), Choi e Syn (2016), Kipp, Beak e Choi (2017), entre outros autores.

Conforme Rafferty (2016, p. 9), vários estudos ao longo da década têm investigado as vantagens ou as desvantagens do "tagueamento" como instrumento de recuperação (GOLDER; HUBERMAN, 2006; MATHES, 2004; MATUSIAK, 2006; MUNK; MORK, 2007; PETERS; STOCK, 2007; TRANT, 2009; GUPTA et al., 2010; ATKEKAR; ZAVERI, 2014 apud RAFFERTY, 2016, p. 9).

Como vantagens e desvantagens, a autora aponta que:

\begin{abstract}
As vantagens incluem o fato de que a marcação é mais barata e econômica em termos de tempo e esforço do que a prática tradicional de indexação, e que o feedback instantâneo [...] derivado do "tagueamento" gerado pelo usuário pode facilitar um alto nível de interação da comunidade que provavelmente não seria possível se as decisões tivessem sido feitas em primeiro lugar sobre os códigos, convenções e regras que governam uma taxionomia rigidamente controlada. As limitações desses sistemas incluem sua ambiguidade, o uso de múltiplas palavras e a ausência de controle de sinônimo, enquanto seus pontos fortes são que eles facilitam serendipidade e navegação (RAFFERTY, 2016, p.9, tradução nossa).
\end{abstract}

Ainda, segundo a autora, verifica-se um avanço no tocante às pesquisas para a indexação ou "tagueamento" e busca por emoção. Nesse sentido, observa-se um movimento para uso da emoção no "tagueamento" em websites (Flickr e Last.fm, entre outros), e projetos examinaram "se e como a indexação da emoção (emotional indexing) ou a "indexação do afeto" (affect indexing) podem ser usadas no gerenciamento de imagens" (RAFFERTY, 2016, p. 10).

De acordo com Golder e Huberman (2006), repositórios de documentos ou bibliotecas digitais podem ser organizadas por palavras-chave atribuídas por uma autoridade, tradicionalmente por bibliotecários. Por outro lado, o "tagueamento" colaborativo é a prática de permitir que qualquer pessoa especialmente os consumidores - adicionem livremente palavras-chave ou tags ao conteúdo. 
O "tagueamento" social (etiquetagem social) ou o "tagueamento" colaborativo, tal como está agora constituído, nas palavras de Kipp, Beak e Choi (2017, p.2365) "começou no final de 2003 com sites como del.icio.us (mais tarde delicious.com)"

Conforme os autores, no decorrer dos anos o conceito de "tagueamento" social foi adotado por muitos outros websites, muitas vezes conhecidos coletivamente como sites de marcadores/favoritos sociais (social bookmarking) ou "tagueamento" social.

Rafferty (2016, p. 8), comenta que uma série de diferentes websites empregam o "tagueamento" social, com base em textos (Cite ULike), música (Last.FM) e imagem (Flickr). Mediante o "tagueamento", relata a autora, os internautas geram palavras-chave para descrever, categorizar ou comentar conteúdo digital.

Para a descrição de tags, consultamos também Guy e Tonkin (2006), a partir da menção de Santarém Segundo e Vidotti (2011), que afirmam, levando em conta uma definição simples, que as tags são " palavras-chave, nomes de categorias ou metadados". Para os autores, elas não são criadas por profissionais da informação, portanto são palavras escolhidas livremente, não seguem nenhuma orientação. Os itens "podem ser categorizadas com qualquer palavra que defina uma relação entre o recurso on-line e um conceito" atribuído mentalmente pelo usuário. Advertem que algumas tags são representações obvias, mas outras ficam sem sentido fora do contexto atribuído pelo autor da etiqueta (GUY; TONKIN, 2006).

No que diz respeito aos conceitos de "tagueamento" e folkosonomia, Kipp, Beak e Choi (2017, p. 2365) descrevem:

No nível básico, "tagueamento" consiste na atribuição de um etiqueta (rótulo) descritivo para um item. Esta etiqueta pode descrever $\mathrm{o}$ assunto de um item ou pode descrever outros aspectos como formato, autor e reações afetivas ao item (Kipp, 2008). As diferenças nas políticas do site permitiram que diferentes tipos de marcação social emergissem. O conjunto de todas as tags sociais atribuídas para um item tornou-se conhecido como uma folksonomia (KIPP; BEAK; CHOI, 2017, p. 2365, tradução nossa). 
Isto é, o "tagueamento" é um processo de atribuição livre de palavras (etiquetas ou tags) pelos internautas aos itens de informação (por vezes citadas como conteúdos) de um serviço on-line no qual se use a folksonomia. As tags são empregadas a fim de organizar o material disponível no sistema, assim como realizar a busca dos arquivos etiquetados.

Santarém Segundo e Vidotti (2011, p. 88), recorrendo à definição de folkosonomia de Thomas Vander Wal (2005), que cunhou o termo, esta é definida como "resultado de atribuição livre e pessoal de tags (etiquetas) a informações ou objetos (recursos na web), visando à sua recuperação".

Sobre as regras de atribuição de tags pelos usuários nos serviços, são citadas duas formas de conceder e que formam dois tipos de folkosonomias, as amplas ou as estreitas:

\begin{abstract}
Embora alguns sites permitissem aos usuários atribuir 0 mesmo termo anteriormente/previamente atribuído por outros usuários (por exemplo, delicious.com), outros sites restringiram os usuários a atribuir apenas tags exclusivas que nunca foram usadas para esse item ou até mesmo restringir a atribuição da tag ao usuário que tinha inicialmente postado o item (por exemplo, Flickr.com). A primeira forma de atribuição [constitui] uma folksonomia ampla de termos [e alguns] sendo usados mais frequentemente assim formando uma sequência longa de termos, ao passo que a segunda forma de atribuição [constitui] uma folksonomia estreita (KIPP; BEAK; CHOI, 2017, p. 2365, tradução nossa).
\end{abstract}

Nesse movimento da atribuição de tags verificam-se recorrentes estudos relacionados com a indexação emocional, considerando que o ambiente da internet estimulou a atribuição livre de palavras aos itens de informação com a participação imediata do internauta. Rafferty (2016, p. 10) cita que "o movimento para digitalizar, colecionar, acessar e produzir documentos culturais na e através da web levou a um maior interesse em desenvolver abordagens para a indexação ou "tagueamento" e busca pela emoção".

Nove anos atrás, Knautz e Stock (2011, p. 979) publicaram artigo sobre a indexação de emoções em vídeos e indicaram a existência de trabalhos sobre o tema no âmbito da música e de imagens. Os autores abordaram o uso do vocabulário controlado para nove emoções que consideraram básicas 
(amor, felicidade, diversão, surpresa, desejo, tristeza, raiva, repugnância e medo), associaram o uso da folkosonomia ampla, bem como uma escala de intensidade para ajustar a emoção sentida. É interessante constatar que 776 participantes indexaram as emoções de 20 vídeos (clips oriundos do Youtube), distinguindo-se as emoções retratadas no vídeo e as evocadas pelo usuário.

Jörgensen (2016), apresenta um panorama atual sobre o contexto das imagens digitais na web aludindo aspectos relacionadas à criação de conteúdos pelos internautas e sua disponibilização, indexação ${ }^{4}$ e recuperação dos conteúdos, aos tipos e práticas de "tagueamento" para fins de acesso e compartilhamento. Assinala que são recursos de informação empregados em uma gama de iniciativas, que vão desde o ensino e a pesquisa para a segurança nacional, ou o objeto de lazer de atividades como jogos e compras. A era digital é marcada pelos princípios da interatividade (dinâmico, controlado pelo internauta, não linear e comportamento de informação complexo), conectividade (senso de comunidade, construção de mundos sociais) e acesso (quebrando barreiras de informação de longa data).
A produção e o uso de sites de mídias sociais alteram a natureza do processo de busca e seus produtos. Os sites de compartilhamento social complementam as bibliotecas tradicionais e digitais, mas também diferem delas de maneira importante e introduzem novos problemas, tendo múltiplos pontos de entrada, desde a descrição fornecida pelo usuário até a indexação mais tradicional (JỔRGENSEN, 2016, p. 144, tradução nossa).

A busca nas mídias sociais é sujeita a poucas regras e, conforme relembra Jörgensen (2016, p. 144), por vezes somente é solicitada a entrada de palavras em uma caixa de pesquisa vazia. Porém, o que mantém-se "em todas essas questões é a necessidade de os usuários entenderem a natureza dos "vocabulários" descritivos usados nesses sistemas, de onde eles vêm, o

\footnotetext{
${ }^{4}$ Jörgensen (2016, p. 165) esclarece e justifica a razão de usar o termo "indexação" para se referir a todos os métodos nos quais os recursos ou atributos da imagem são descritos nos diversos níveis para busca e recuperação (catalogação, indexação, classificação, catalogação e metadados).
} 
que motiva sua criação, as coleções que eles brotam e os objetivos de busca que eles podem preencher".

Sobre os diversos aspectos relevantes abordados por Jörgensen (2016) quanto ao "tagueamento" de informações visuais, destacam-se e elencam-se os que seguem:

- as tags atribuídas pelo usuário variam muito na formação das palavras, níveis de descrição e significado semântico. Podem ser qualquer parte do discurso (substantivo, verbo, adjetivo, etc.) ou forma (singular ou plural) e possuir várias palavras. As tags podem ter erros de digitação, palavras sem sentido, nomeações confusas ou equivocadas, ou possuir significado somente para o criador. Os principais problemas observados com as tags são tanto sintáticos (erros ortográficos, palavras combinadas) quanto semânticos (sinonímia, ambiguidade, polissemia, falta de hierarquia e relacionamentos).

- a busca de imagem é mais comumente realizada no nível básico (maçã) da linguagem do cotidiano, o qual nem é o mais abstrato ou geral (fruta), confirmando a pesquisa realizada por Rorissa e lyer (2008) já citada neste artigo. Alerta que o fator cultural influência na determinação da nomeação e que esta pode se modificar ao longo do tempo, além da influência dos níveis de especialização. Sobre a ausência de tags nos itens, identificou que os taggers ("tagueadores") adicionam nomeações genéricas e os internautas hesitam em excluir tags incorretas existentes, mesmo quando é solicitado de forma explícita. Em um dos estudos analisados pela autora, identificaram-se buscas de informações na web em geral tipificadas por consultas curtas (uma ou poucas palavras). Alguns pesquisadores demonstram que são realizadas pesquisas para pessoas específicas, eventos ou atividades, mas da mesma forma são feitas consultas para tipos mais gerais de imagens ou necessidades abstratas/ subjetivas e, em especial, quando são realizadas navegações em vez da formulação de consultas. Por outro lado, outros pesquisadores demonstraram que as consultas conceituais dominam as buscas. Jorgensen (2016) cita seu estudo de 1998 e ainda Choi e Rasmussen (2003); Hollink et al.(2004); e Chung e Yoon (2011). 
- a ausência de política de marcação de tags entre as organizações é vista como um desafio tanto para os pesquisadores como para os internautas, pois causam inconsistências nos serviços (por exemplo: quem pode fazer as marcações ou fornecer orientação; edição do conteúdo, limitação da exibição das tags, entre outros). Diante disso, a autora aponta como prematuro tirar conclusões definitivas sobre o "tagueamento".

- as tags possuem várias funções para os internautas (gerenciamento de informação pessoal, comum na literatura os autores enfocam o "tagueamento" de imagens sobre a eficácia do seu potencial como ferramenta de descoberta).

- dois fatores motivam o tagger. organização ou comunicação (o "porquê" de descrever); e "tagueamento" para si mesmo ou para outros (família e amigos, público), o "quem".

- alguns fatores contextuais que afetam a criação de tags e sua influência na quantidade (saída) e na qualidade das etiquetas, entre eles: motivações individuais entre taggers; a natureza social da marcação nas comunidades de prática; domínio; a natureza de uma imagem; • tarefa a ser realizada; concepção/projeto do sistema.

- a compreensão das diversas variáveis que influenciam no processo de "tagueamento" serão são importantes para orientar os criadores de sistemas e os pesquisadores de imagens. Em consequência, as pesquisas sobre "tagueamento" procuram explorar questões de amplo alcance, entre elas:

- As tags se encaixam nos modelos existentes ou propostos para o conteúdo da imagem, ou são necessários novos modelos / combinações de modelos?

- As tags têm uma relação útil para as buscas de imagens? - Como as tags se comparam ao vocabulário controlado e aos metadados formais em termos de qualidade e funcionalidade de recuperação?

- Quais fatores contextuais (motivação do tagger", domínio, tarefa e design do sistema), afetam as tags e a produção do "tagueamento"? (JÖRGENSEN, 2016, p. 143-154, tradução nossa).

Por fim, concerne retornarmos à menção ao estudo realizado por Kipp, Beak e Choi (2017) sobre o tema, no qual verificaram as motivações e as 
intenções dos usuários no uso de coleções institucionais de imagens em sites de tagueamento social. Para isto, foram coletados dados de usuários na Coleção Flickr da Biblioteca do Congresso. Sobre o método, os autores explicam que o estudo usou a plataforma Qualtrics e o idioma inglês, embora alguns usuários tenham encaminhado respostas em outras línguas (principalmente em francês):

Nós distribuímos a pesquisa por meio do correio Flickr no outono de 2012 para cada participante, um total de 7,563 participantes. Os autores enviaram algumas pesquisas, pois 0 correio do Flickr tem limites rigorosos sobre o número de usuários que podem ser contatados por dia e por semana. A pesquisa demorou vários meses [...], mas esse método garantiu que todos os usuários contatados ainda eram ou tinham sido usuários do Flickr e realmente contribuíram para a coleção LC Flickr em algum momento do passado. Nós completamos o envio da pesquisa em 14 de dezembro de 2012. Tivemos 1.708 pesquisas devolvidas, resultando em um nível de participação de $21 \%$, o que é uma boa taxa de resposta para uma pesquisa na web (KIPP; BEAK; CHOI, 2017, p. 2367, tradução nossa).

Como se observa, a pesquisa teve um retorno de respostas considerável, embora o total de formulários enviados tenha sido bem maior. Estas devem ser apreciadas como indícios substâncias para o objetivo da pesquisa, porém tendo em vista o tipo de coleção, natureza da imagem, orientações sobre o "tagueamento", e demais variáveis envolvidas. Os resultados foram categorizados em 11 motivações: reações afetivas (emocionais), opinião sobre a foto, interesse no assunto, contribuição para descrição, compartilhamento de conhecimento, melhoria de encontrabilidade (para outros, e para melhorar a busca e o resultado), rede social, apreciação, uso pessoal e relacionamento pessoal. Tais motivações resultaram em três categorias de agrupamento: (a) pessoal, (b) afetivo e (c) social. Sendo que a categoria das motivações afetivas (e emocional) foi a mais recorrente. Os autores identificaram que as reações afetivas às imagens desempenham um papel central na motivação dos usuários para marcar, favorecer ou comentar. As motivações dos usuários diferiram por profissões. 
Como mencionado na literatura, esses estudos sobre o comportamento de busca e "tagueamento" de imagens e audiovisuais pelos internautas são importantes e fazem parte da sociedade contemporânea que vivemos, contudo esses estudos sobre a nomeação de conceitos e emoções abstratos identificados nos documentos já levantaram questões sobre sua utilidade. Parecem ser contribuições viáveis, com as devidas interlocuções de áreas, para a realização da indexação profissional seja em ambiente web ou não. Justifica-se rememorar que Lancaster (1993, 2004), entre outros autores, abordou essa discussão no âmbito da indexação e resumos das obras de ficção. Porém, segundo Jörgensen (2016, p. 154), os métodos de Contentbased retrieval (CBR ou CBIR) há muito alertaram sobre a cautela que deve-se ter na inclusão de aspectos interpretativos ou subjetivos, qualidades que não podem ser diretamente e corretamente percebidas nos objetos retratados ou textos.

\section{CONCLUSÕES}

A partir da literatura consultada para o embasamento teórico deste artigo, em consonância com o esforço de reflexão da sua autora na prática acadêmica no ensino e pesquisa, percebe-se a abordagem de três das dimensões mencionadas, contudo a dimensão da problematização e caracterização dos cenários sociais, culturais, econômicos, políticos, tecnológicos, entre outros, que abrigam acervos ou serviços de imagens e audiovisuais carecem de uma maior contextualização, particularização e exposição.

Não se ponderar as quatro dimensões para o delineamento de uma pesquisa relacionada à informação visual, no contexto dos objetos culturais digitais ou não, é enfraquecer a avaliação de variáveis que atuam no fenômeno de pesquisa e, em consequência, na solidez dos resultados.

No que tange à terceira e quarta dimensões, particularizou-se a discussão no artigo e evidenciou-se a reverberação da literatura sobre a prática do "tagueamento" no espaço da web. Observou-se igualmente a discussão 
sobre a indexação profissional e a "indexação" não profissional realizada pelos taggers e como esta última, ou seja, o "tagueamento" colaborativo/social tem sido considerado pelos serviços de informação e indexadores. Entre outras abordagens, na literatura analisada são recorrentes os estudos que procuram determinar a relação cognitiva da atribuição de tags (etiquetagens livres) nas consultas dos usuários (internautas). Pesquisas têm avançado quanto à indexação (ou "tagueamento") e busca de imagens e audiovisuais por emoção (distinguindo-se as emoções retratadas no audiovisual ou imagem e as evocadas pelo usuário), bem como as motivações e as intenções dos usuários no uso de coleções institucionais de imagens em sites de "tagueamento" colaborativo/social.

\section{REFERÊNCIAS}

AMERICAN FILM INSTITUTE. About the AFI catalog. Los Angeles, 2017. Disponível em: <http://www.afi.com/catalog/about/>. Acesso em: 12 set. 2017.

ARAÚJO, C. A. Á. Arquivologia, biblioteconomia, museologia e ciência da informação: o diálogo possível. Brasília, DF: Briquet de Lemos; São Paulo: Associação Brasileira de Profissionais de Informação, 2014.

BAR-ILAN, J. et al. Tag-based retrieval of images through different interface: a user study. Online Information Review, v. 36, n. 5, p. 739-757, 2012.

BORGES, M. E. L.. História \& fotografia. Belo Horizonte: Autêntica, 2005.

CHOI, Y.; RASMUSSEN, E. M. Searching for images: the analysis of users' queries for image retrieval in american history. Journal of the American Society for Information Science and Technology, v. 54, n. 6, p. 498-511, 2003.

CHOI, Y.; SYN, S. Y.. Characteristics of tagging behavior in digitized humanities online collections. Journal of the Association for Information Science and Technology, New York, v. 67, n. 5, p. 1089-1104, 2016.

CHUNG, E.; YOON, J. Image needs in context of image use: an exploratory study. Journal of Information Science, v. 37, n. 2, p. 163-177, 2011.

DAHLBERG, I.. Classification system for knowledge organization literature. Knowledge Organization, Wurzburg, v. 20, n. 4, p. 213, 1993. 
FOSTER, A.; RAFFERTY, P.. Managing digital cultural objects: analysis, discovery and retrieval. London: Facet Publishing, 2016.

GOLDER, S. A.; HUBERMAN, B. A. Usage patterns of collaborative tagging systems. Journal of Information Science, Cambridge, v. 32, n. 2, p. 198-208, 2006.

GUY, M.; TONKIN, E.. Folksonomies: tidying up tags? D-Lib Magazine, Reston, v. 12, n. 1, Jan. 2006.

HOLLINK, L. et al. Classification of user image descriptions. International Journal of Human-Computer Studies, v. 61, n. 5, p. 601-626, 2004.

JORGENSEN, C. Attributes of images in describing tasks. Information Processing and Management, v. 34, n. 2-3, p.161-174, 1998.

JÖRGENSEN, C. Photos: flickr, facebook and other social networking sites. In: FOSTER, Allen; RAFFERTY, Pauline. Managing digital cultural objects: analysis, discovery and retrieval. London: Facet Publishing, 2016. p. 143-181.

KIPP, M. E. I.; BEAK, J.; CHOI, I.. Motivations and intentions of Flickr users in enriching flick records for Library of Congress photos. Journal of the

Association for Information Science and Technology, Medford, v. 68, n. 10, p. 2364-2379, 2017.

KNAUTZ, K.; STOCK, W. G. Collective indexing of emotions in videos. Journal of Documentation, London, v. 67, n. 6, p. 975-994, 2011.

LA BARRE, K.; CORDEIRO, R. I. de N.. Film retrieval on the web: sharing, naming, access and discovery. In: FOSTER, A.; RAFFERTY, P.. Managing digital cultural objects: analysis, discovery and retrieval. London: Facet Publishing, 2016. p. 199-217.

LANCASTER. F. W. Da indexação e redação de resumos de obras de ficção. In:_ Indexação e resumos: teoria e prática. Brasília: Briquet de Lemos/Livros, 1993. cap. 12, p.188-199.

LANCASTER. F. W. Da indexação e redação de resumos de obras de ficção. In:_ Indexação e resumos: teoria e prática. 2. ed. Brasília: Briquet de Lemos/Livros, 2004. cap. 12, p.199-213.

LANGRIDGE, D. W. Subject analysis: principles and procedures. London: Bowker-Saur, 1989.

LE COADIC, Y-F. A ciência da informação. Brasília: Briquet de Lemos, 1996. 
LIMA, I. A fotografia é a sua linguagem. Rio de Janeiro: Espaço e Tempo, 1988.

MENESES, U. T. B. de. Fontes visuais, cultura visual, história visual: balanço provisório, propostas cautelares. Revista Brasileira de História, São Paulo, v. 23, n. 45, p. 11-36, jul. 2003.

RAFFERTY, P.. Managing, searching and finding digital cultural objects: putting it in context. In: FOSTER, A.; RAFFERTY, P.. Managing digital cultural objects: analysis, discovery and retrieval. London: Facet Publishing, 2016. p. 323.

RANSOM, N.; RAFFERTY, P.. Facets of user-assigned tags and their effectiveness in image retrieval. Journal of Documentation, v. 67, n. 6, p. 1038-1066, 2011.

RENDÓN-ROJAS, M. Á. Epistemologia da ciência da informação: objeto de estudo e principais categorias. InCID: revisa de ciência da informação e documentação, Ribeirão Preto, v. 3, n. 1, p. 3-14, jan./jun. 2012.

RORISSA, A.; IYER, $\mathrm{H}$. Theories of cognition and image categorization: what category labels reveal about basic level theory. Journal of the Association for Information Science and Technology, v. 59, n. 9, p. 1383-1392, July 2008.

SALAÜN, J-M; ARSENAULT, C. Introduction aux sciences de l'information. Montreal: Les Presses de d'Université de Montréal, 2009.

SANTARÉM SEGUNDO, J. E.; VIDOTTI, S. A. B. G.. Rede de tags para recuperação da informação no contexto da representação interativa. InCID: revista de ciência da informação e documentação, Ribeirão Preto, v. 2, n. 1, p. 86-109, jan./jun. 2011.

WAL, T. V.. Folksonomy definition and wikipedia. Disponível em: $<$ http://www.vanderwal.net/random/entrysel.php?blog=1750 . Acesso em: 13 mar. 2017.

WELLISCH, H. H. Indexing from A to Z. 2. ed. New York: H. W. Wilson, 1995.

\section{THE DELINEATION OF AN IMAGE AND AUDIOVISUALS RESEARCH IN INFORMATION SCIENCE: TAGGING AS THE FOURTH DIMENSION}

\footnotetext{
ABSTRACT

Introduction: There are four converging dimensions when delineating an image and audiovisuals research in the field of Information Science and, more particularly, in the context of visual information organization.
} 
Objective: To indicate that an images and audiovisuals study is more densely substantiated when the following dimensions are pondered on during the research: the specialty of the Information Science involved, as well as the interface areas or chosen operational field; the nature of the analysis corpus; related social, cultural, economic scenarios, among others, to physical or digital informational environments; the state of the art of the literature.

Methodology: Theoretical reflection based on the literature addressing indexing for the representation and the access of the object of study in information environments.

Results: The four dimensions have an impact on the variables determination that must be considered in a research concerning visual information and reached results, considering that this information universe is gigantic and full of peculiarities. Regarding the fourth dimension, the articles on collaborative/social tagging that try to determine the cognitive relation of tag attribution (free labelling) during searches, stand out from the rest of the literature on image and audiovisuals in the context of indexing and information search.

Conclusion: In the analyzed literature, the three mentioned dimensions are observable. However, the problematization dimension of the characterization of the scenarios lack a bigger exposure.

Descriptors: Image research. Audiovisuals research. Image indexing. Audiovisuals indexing. Collaborative/social tagging.

\title{
LA CONFIGURACIÓN DE UNA INVESTIGACIÓN EN IMÁGENES Y AUDIOVISUALES EN CIENCIA DE LA INFORMACIÓN: EL ETIQUETAMIENTO COMO CUARTA DIMENSIÓN
}

\begin{abstract}
RESUMEN
Introducción: Se abordan cuatro dimensiones convergentes del diseño de una investigación en imágenes y audiovisuales en el ámbito de Ciencia de la Información y, en particular, del contexto de la organización de información visual.

Objetivo: Señalar que un ensayo de imágenes y audiovisuales se basa con mayor densidad cuando las siguientes dimensiones están ponderadas (aclaradas) en la investigación: la implicación de especialidad de la Ciencia de Información, así como las áreas de interfaz u la elección de campos operacionales; el carácter del corpus de análisis; los escenarios sociales, culturales, económicos, entre otros, relacionados, sean en entornos informacionales físicos o digitales; y la situación del arte de la literatura.

Metodología: Reflexión teórica con base en literatura que plantea el índice para la representación y el acceso al objeto de investigación en lugares de información.

Resultados: Las cuatro dimensiones afectan la determinación de variables que deben ser consideradas en una investigación acerca de informaciones visuales y en los resultados alcanzados, teniendo en consideración que ese universo de informaciones es enorme y lleno de peculiaridades. En cuanto a la cuarta dimensión se sobresale acerca de la literatura de imagen y de audiovisuales en el ámbito de la indización y busca por información, los artículos sobre el "etiquetamiento" colaborativo/social, los cuales intentan determinar la relación cognitiva de atribución de "tags" (etiquetajes libres) en consultas.
\end{abstract}


Conclusiones: En la literatura analizada se nota el enfoque de tres dentre las dimensiones mencionadas, sin embargo la dimensión del cuestionamiento y caracterización de los escenarios requiere mayor exposición.

Descriptores: Investigación en imágenes. Investigación audiovisuales. Indización de imágenes. Indización audiovisuales. "Etiquetamiento" colaborativo/social. 